\title{
A review on techniques for improving the mechanical properties of fusion welded joints
}

\author{
J. Kalpana ${ }^{a}$, P. Srinivasa $\operatorname{Rao}^{b}$ and P. Govinda Rao ${ }^{c^{*}}$
}

${ }^{a}$ Department of Mechanical Engineering, SSCE, Chilakapalem, Andhra Pradesh, India

${ }^{b}$ Department of Mechanical Engineering, Centurion University, Parlakhemundi, Odisha, India

${ }^{c}$ Department of Mechanical Engineering, GMRIT, Rajam, Andhra Pradesh, India

\begin{tabular}{l}
\hline A R T I C L EI N F O \\
\hline Article history: \\
Received 6 June, 2017 \\
Accepted 12 September 2017 \\
Available online \\
12 September 2017 \\
\hline Keywords: \\
Post Weld Heat treatment \\
(PWHT) \\
Pulsed current welding \\
Hybrid welding Vibratory \\
assisted welding and mechanical \\
properties
\end{tabular}

\section{A B S T R A C T}

\begin{abstract}
This paper presents the effect of Post Weld Heat Treatment (PWHT), pulsed current welding, hybrid welding and vibratory assisted welding in the weld quality, residual stresses and mechanical properties of welded joints. At last, vibratory assisted welding has been suggested to enhance the mechanical properties of welded joints by overcoming the drawbacks in the above stated techniques. Past results showed that the welded test specimens under vibratory conditions exhibited improvements in mechanical properties than the arc welding without vibrations. Finally, some literature gaps are clearly identified and these gaps could help the future generation researchers to do work in the new direction.
\end{abstract}

(C) 2017 Growing Science Ltd. All rights reserved.

\section{Introduction}

Welding provides a permanent joint but it affects the metallurgy of the components. During the welding process, due to the intense heat input, the regions near the weld undergo severe thermal cycles, thereby generating inhomogeneous plastic deformation in the weldment. Due to this, strength of the weld joint is reduced. To overcome this, different methods are used to improve the mechanical properties of welded joints. These methods including post weld heat treatment, pulsed current, hybrid welding, vibratory assisted welding are described and reviewed in this paper. After reviewing the available literature for each welding technique, it was concluded that the recently developed vibratory assisted welding has some advantages and benefit which can eliminate the shortcomings of the previous and conventional fusion welding methods.

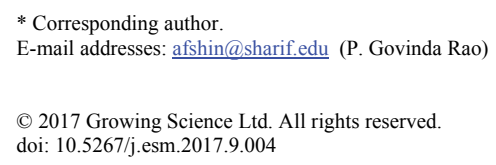


Post Weld Heat Treatment is one type of heat treatment process applied to welded joints after completion of the welding process to improve mechanical properties and reduce the brittle fracture of welded joints by changing the metallurgical structure. But, PWHT requires special tools and consumes more time to complete the process. A number of researchers have studied the effect of PWHT on mechanical properties and microstructure of joints (including tensile strength, impact strength and hardness) made of different materials such as AA2219 aluminium, AA6661, Cr-MoBoiler Steel, pressure vessel steel, 2205 duplex stainless steel, stainless maraging steel, and manufactured by different fusion welding methods such as Gas Metal Arc welded (GMAW), laser welded, polarity TIG welded (Ding et al., 2014; Smith et al., 1997; Ibrahim et al., 2013; An et al., 2012; Zhu et al., 2015; Badji et al., 2004; Gomes et al., 2013; Ahmad et al., 2011; Ahmed et al., 2015). For example, Ding et al. (2014) used PWHT method to the TIG weldedAA2219 aluminium alloy joints with the solution treatment for $30 \mathrm{~min}$ at temperature $535^{\circ} \mathrm{C}$, followed by water quenching and artificial aging for 12 hours at temperature $175^{\circ} \mathrm{C}$ to improve the properties of the welded joints. Significant improvement in impact toughness of a multi pass submerged arc welded joint was reported by Smith et al. (1997) when the PWHT technique was applied for a period of 40 hours at $620^{\circ} \mathrm{C}$.

As another welding technique, pulsed current welding is the process of pulsing the current during welding process. This is developed for controlling metal transfer at low mean current levels by imposing short duration high current pulses to improve the mechanical properties of weldments. In this regard, several papers have been published to investigate the influence of this method on hardness, tensile strength, residual stress field and ductility of different materials including titanium matrix composites, aluminium 6061-T6 alloy, DP980 steel, C-276 alloy, SS304 steel, AA6082-T6 Aluminium alloy (Mao et al., 2014; Raveendra \& Kumar, 2013; Aliha \& Gharebaghi, 2017; Sawanishi et al., 2014; Balasubramanian et al., 2008; Manikandan et al., 2014; Ravindra et al., 2013; Ravikumar et al., 2014). In the aforementioned researches, some techniques including conventional GTAW method, Pulsed Current Gas Tungsten Arc Welding (PCGTAW), continuous current GTAW and continuous current GMAW have been investigated and compared together. As an example, Manikandan et al. (2014) experimentally showed that the tensile strength of welded joints is increased when using pulsed current welding technique compared to the non-pulsed current welding.

Hybrid welding is another way of improving the mechanical properties of weldments. It is a type of welding process that combines the principles of one type of welding to another type of welding to enhance the properties of weldments. There are mainly three types of hybrid welding processes depending on the arc used. Those are TIG-laser welding, plasma arc-laser welding and MIG augmented-laser welding. But, MIG-laser hybrid welding has been entered into industrial applications, even though firstly, research was on TIG-augmented laser welding, when compared to MIG-laser welding. For example, Li et al. (2013) found that shear strength of T-joints was improved to $90 \%$ of base metal in hybrid welding of laser-gas tungsten arc welding (GTAW), when compared to joints produced with only laser welding or only gas tungsten arc welding (GTAW). Dai et al. (2015) found that the Gas Tungsten arc Welding (GTAW) - assisted hybrid ultrasonic seam welding for direct joining of $1 \mathrm{~mm}$ thick Mg AZ31B and A16061alloy sheets was successfully welded for improving the tensile shear strength of joint. Shibata et al. (2006) also investigated the tensile strength of laser-MIG hybrid welded joint with and without filler wire. Based on Leo et al. (2015) by decreasing the welding voltage and current, in this welding technique, the corresponding tensile strength and micro-hardness values are increased. However, any of the aforementioned welding methods have own shortcomings and drawbacks which more details about them can be found in Ramakrishna et al. (2016). In the next section, the benefits of using another welding technique called vibratory assisted welding for increasing the integrity and reliability of weldments is reviewed.

\section{Vibratory Assisted Welding}

Normal welding operation has so many defects like undercuts, slag inclusions, spatter, surface porosity, and lack of fusion. The major weld defects are due to the residual stresses produced during the welding process and this leads to the reduction in the weld quality. To avoid the weld defects and 
improve the quality of weldments, vibratory assisted welding is introduced recently. Fig. 1 shows the experimental set up used for VAW process. A comprehensive literature review in this regard is presented here.

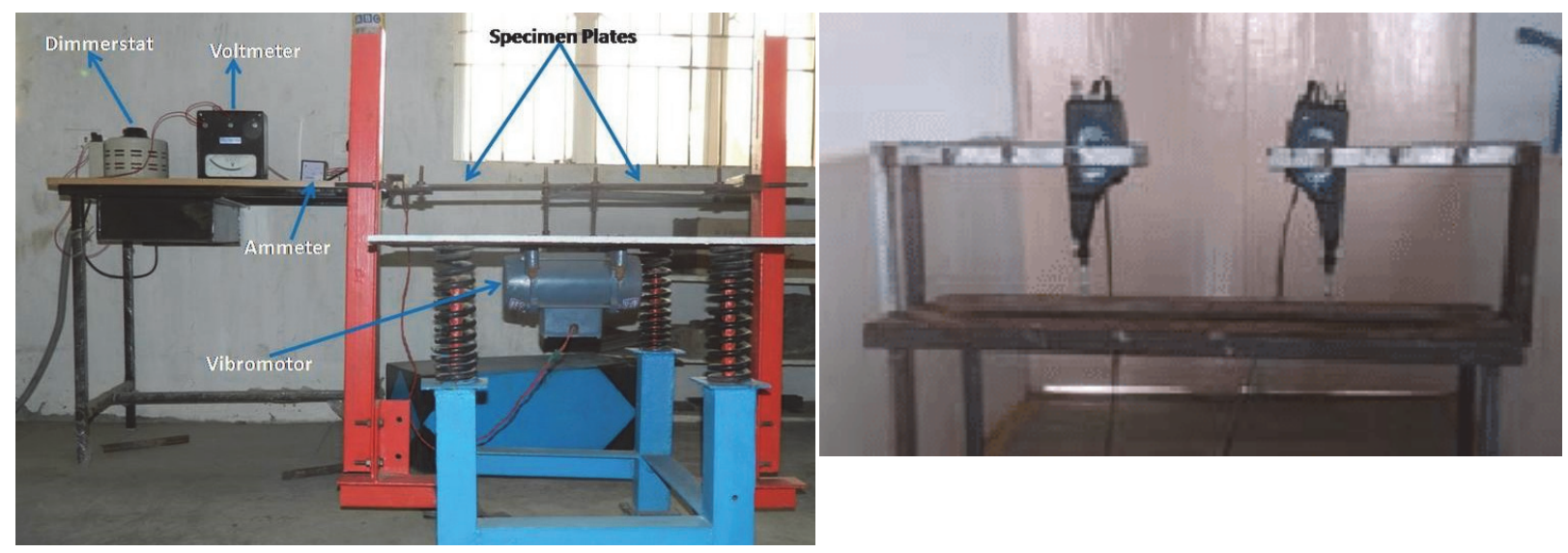

Fig. 1. Fixture and setup used for vibratory assisted welding (Rao et al., 2017)

Xu et al. (2007) studied the effects of vibratory weld conditioning (VWC) on the residual stress and distortion in multi-pass girth-butt welded pipes through comparison between VWC and normal submerged arc welding. Their results showed that VWC can reduce the residual circumferential stresses at the outer surface and the distortion in radial direction. Rao et al. (2007) examined the cyclic stress and strain of type 304L stainless steel welded specimens and presented the cyclic creep mechanism during VSR (vibratory stress relief) of 304L. A mathematic model of residual stress relaxation is proposed which was conducted against dynamic stress. Their model is applied to evaluate the effectiveness of vibratory stress relief during manufacturing HT-7U Tokamak welded structure. Lu et al. (2008) studied the effect of VWC on the welded joint properties. Cylinders having different thicknesses were welded by submerged arc welding (SAW). Their experiment results shown that the vibration applied during welding generally reduces the residual deformation and stress. Qinghua et al. (2007) found the effect of vibrations given during submerged arc multi-pass welding for improving the quality of fully weld valve. Cylinders having different thickness were tested. The residual deformation and stress due to each pass of welding have reduced in vibratory weld conditioning (VWC). The results indicated that effects of vibration on impact property mechanics is complex.

Sun et al. (2004a) carried out experiments on Vibratory stress relieving of D6AC and D406A welding steel plates. There is decrement in macro-residual stress up to $25 \mathrm{MPa}$, which is the same value as can be achieved by hot stress relief. Jia et al. (2014) studied the textures and crystallographic orientations beneath the treatment area in AA 6061 aluminium alloy after vibratory stress relief (VSR) process by combining the electron backscatter diffraction analysis of the disoriented low- or high-angle boundaries, the (inverse) pole figures, the line scans and the various orientations of grains. The effect of relaxation is due to compressive residual stress in the intermediate region to that of tensile residual stress on both sides of the cantilever by means of X-ray diffraction. Sun et al. (2004b) introduced the vibratory stress relief to the bar steel that was shaped into marine shafting. The tensile strengths of the steel bars were measured before and after vibration. While the steel bar was vibrating, vibratory stresses were measured at six different locations of axial surface with dynamic strain gauge. The macro residual stress was measured with X-ray stress meter before and after vibration, the macro residual stress decreased notably by $48 \%$. The tensile strength slightly changed.

Xin et al. (2008) studied that the vibrations given during welding reduces the residual deformation and stress. The yield strength, as well as the tensile strength, does not change distinctively in vibratory SAW (V-SAW) when compared with that in normal SAW (N-SAW). The bend property has been improved in V-SAW. Fracture test was carried out using single edge notch bend (SENB) specimens. The fracture surfaces of failed weld metal (WM) specimens were observed by dimple-like 
structures. The depth and the density of these dimples are increased after the vibration given in welding. Marking of river, the characteristic of cleavage fracture was observed in the heat-affected zone (HAZ) of specimens. Lu et al. (2007a,b) studied on vibratory stress relieving (VSR) was applied to largedimensional pipes with straight and bending formation. The results indicate that VSR has positive effect on as-cast structure such as the weld beam, but has unfavourable influence on structure with cold plastic forming. The average value of the residual stress in the weld beam was reduced significantly after VSR, while the stress in the bending line is increased. The difference between the pipe end and the pipe centre in residual stress is evident. Kuo et al. (2007) investigated the use of vibrations to decrease the residual stress arised from the welding process. The existing methods for relieving residual stress from welds are: mechanical, beat and electromagnetic. The mechanical method may be performed by hammering or vibration. The heat method consists of heating the whole welded piece or each weld, one by one. The electromagnetic method uses the electromagnetic hammer technique. In the beat treatment the part is heated until the yield point is reduced to less than the residual stress, which would affect the local plastic distortion, decrease of the residual stress intensity and reduction of hardness. Rao et al. (2007) performed Gas tungsten arc welding (GTAW) on AISI 304 stainless steel; vibrations were induced by an eccentric motor. The vibration weld shows a very small ferrite structure, uniform composition distribution, low residual stress and low ferrite content relative to the weld without vibration. The results illustrate that the vibration reduces the micro super cooling and improves the nucleation of ferrite to form a grain refined structure. Vibrations were induced to cause stacking faults. These are identified as the major cause of the line broadening of X-ray diffraction profile.

$\mathrm{Xu}$ et al. (2006) studied on effects of vibratory weld conditioning (VWC) on the residual stresses and transverse contraction distortions compared with normal welding in submerged arc multi pass welding. The results showed that VWC could reduce the residual stresses greatly and make the distribution of residual stresses uniform. Moreover, VWC could also decrease transverse contraction distortions greatly. Teng et al. (2006) studied on vibratory submerged arc welding which was a new welding process to improve welding quality by giving vibrations to plates. The test of thick plate welding using vibratory welding of valve in west-to-east gas pipeline was introduced, and then normal welding was compared with vibratory submerged arc welding in residual stress, distortion and microstructures. The results of test showed that vibratory submerged arc welding can reduce residual stress and distortion notably and make the grains fine and improve the properties of welded joint. Firstly, electro-slag weld was done in the two kinds of vibration condition: $0.3 \mathrm{~g}$ and $0.6 \mathrm{~g}$. Then, the distribution of welding residual stress was measured with blind hole-drilling method. Results show vibratory weld conditioning can relief welding residual stress greatly and max is less than $1 / 2 \mathrm{~s}$. From metallography, vibratory weld conditioning can refine the grain effectively.

Yang et al. (2005) developed a finite element model to simulate the vibratory stress relief after welding. Both resonant and non-resonant vibrations can relieve residual stresses in welded structures by creating plastic deformation around the weld area. For the non-resonant vibration, the stress reduction strongly depends on the vibration amplitude. For the resonant vibration, the vibration frequency is the key for stress relief. The vibration frequency should be close to the structure natural frequency for the desired vibration mode. Only small vibration amplitude is needed, which will be amplified during vibration. Vibration time does not have a major impact on the vibration stress relief. The larger the amplitude that the vibratory stress relief has, the better the treatment. Rao et al. (2005) studied on the process of vibratory stress relief (VSR) to reduce the residual stress after welding of stainless steel plate. The effectiveness of the process is evaluated according to the JB/T5926-91 (Chinese) VSR standard. The residual stresses before and after VSR on the weld bead of the plate are measured to show the reduction and redistribution of stress. The results quantitatively show the effectiveness of the VSR process and prove that the process is a practicable alterative to heat treatment for reduction of residual stress.

Sun et al. (2004) studied on vibratory stress relieving of D6AC and D406A welding plate. The welding plates were tempered at $310^{\circ} \mathrm{C}$, to decrease the macro-residual stress to a lower value, and to 
kill of the micro-residual stress peak value. The vibratory stress relief of D6AC and D406A welding steel plates was carried out under the lower macro-residual stress state. Results showed that the macroresidual stresses in the welded steel plates of D6AC and D406A were decreased to Zero-stress point and the vibratory stress relief can replace the hot stress relief. Dryga (2002) studied on operation of end bracket of large power equipment. High reliability and quality of the bracket should be considered. After cutting the billets, welding, and mechanical treatment, parts of the end brackets should be processed with the use of vibratory stabilizing treatment in order to reduce residual stresses and provide stable sizes of the parts. The parts are manufactured from steel of St. 3 grade. Investigations of residual stresses in the parts have been performed. Results of the investigations have been presented. They confirm high efficiency of vibratory stabilizing treatment.

Munsi et al. (2001a) studied on how vibratory stress was applied to mild steel specimens during welding and observing its influence on the residual stress, microstructure and hardness of the material. Residual stresses were decreased with respect to vibration whether it was applied during welding or after the joint was made. It was observed that the applied stress effected the grain growth process in the weld. As a result the hardness of the material was increased by 25 per cent. In another research work, Munsi et al. (2001b) studied the effect of torsional vibration on residual stresses. Three types of shaft specimen were processed, namely (i) a homogeneous material shaft, (ii) a shaft was welded on a circumferential line and (ii) a spot-welded shaft. The first two types of shaft exhibited distribution in the residual stresses under the given torsional loads. On the spot-welded shafts the residual stresses were decreased significantly at a very low level of vibration. Furthermore, Munsi et al. (2001c) studied on welded specimens that were processed after being cooled to room temperature, with varying amplitude of given stress and vibration period. An increase in the applied stress led to a significant decrease in the residual stresses. The influence of time of vibration was observed to be very small for a lower range of applied stresses $(<230 \mathrm{MPa})$; an increase in the period of vibration had no effect on residual stresses. At higher applied stresses $(>230 \mathrm{MPa})$, the residual stresses were redistributed with increasing time period of vibration. It is shown that the energy concept of the vibratory stress relief mechanism was not validated. Munsi et al. (2000) studied to investigate the use of vibration to reduce the residual stress coming from the welding. Butt weld joints were subjected to vibration immediately after welding. During the specimens were cooling, vibration was given to them over a specific range of temperatures. Three batches of specimens processed in three regions of temperatures. The residual stresses were measured using an automated scanning X-ray diffractometer which given the completed data over the area close to the weld and in the heat-affected zone. The residual stresses were changed with an increase at some given stress-temperature combinations and a decrement in others. With a suitable choice of vibratory treatment, welding stresses may be brought within desired design parameters. Munsi et al. (1999) studied the effect of rigid body motion vibration on welding residual stresses. The specimens were welded during vibrations in a rigid body motion mode. The specimens were vibrated using two different frequencies $(50 \mathrm{~Hz}$ and $500 \mathrm{~Hz})$. At the low frequency of vibration $(50 \mathrm{~Hz})$, small changes in the residual stresses were found and there was no particular trend. At the high frequency vibration, no significant reductions in the residual stresses in the longitudinal stresses or in the transverse direction were observed. Some initial results are presented also regarding flexural vibration effects. Rao et al. (2012) describes a dynamic solidification technology, by giving mechanical vibrations during welding process. Later analysis was carried out for mild steel pieces having $5 \mathrm{~mm}$. of thick plate butt welded joints. The results exhibited from the current study pointed out that the butt welded joints fabricated with vibrations were had relatively high hardness, without any considerable loss in its ductility. Balasubramanian et al. (2011) made an attempt to reduce the hot cracking and to refine the fusion zone grains in welding of aluminium alloys through vibratory treatment. The material used for the investigation is AA7075 aluminium alloy. Vibrations applied in the frequency range of $100 \mathrm{~Hz}$ to $2050 \mathrm{~Hz}$ and results are compared using weld cracking tests and other characterization tests. Test results show that by applying vibratory treatment, hot cracking can be largely controlled in arc welding. Prakash et al. (2010) found the dynamic solidification effect and changes in mechanical properties under vibratory weld treatment. Welding with vibrations has the advantages of low investment, more suitable operation, lesser amount of pollution and less manufacturing time period. In vibratory welding, work piece vibrates during welding process and it mainly influences the welding 
solidification to enhance the quality. Hsieh et al (2014) pointed out that simultaneous vibration welding gives primary $\delta$-ferrite was refined and the morphologies of retained $\delta$-ferrite attains discontinuous so that $\delta$-ferrite contents reduced. The smallest content of $\delta$-ferrite $(5.5 \%)$ occurred using the eccentric circulating vibrator. The diffraction intensities were reduced and the FWHM widened with both with vibration and without vibration. A residual stress can obviously be enhanced, producing an excellent effect on stress relief at a resonant frequency. The stress relief effect with an eccentric circulating vibrator was better than that obtained using a magnetic telescopic vibrator. Varga et al. (2008) describes propylene homo- and copolymers (both random and block types) with and without beta nucleation were injection moulded and the related plaques joined by linear vibration welding. The melt flow index (MFI) of the polypropylenes was different. During vibration welding the pressure has been varied $(0.5$, 2 and $8 \mathrm{MPa}$ ). The properties of the welded plaques were determined under both static (tensile) and dynamic conditions (Charpy impact). Boonstra et al. (2006) described vibration welding of wood that has been preheated according to an industrial two-step process indicates that such wood can be welded and can yield welded joints of good strength. The joint strength is; however, markedly lower than obtained when welding non-heat-treated timber. In general, weld strength of the timber is poor if welding is done on hydro thermolyzed wood. The strength results are instead much better if welding is done at the end of the complete heat treatment process, i.e., after the dry heat step in weldlines obtained after hydro thermolysis an increase in rigidity and brittleness of the wood cells is observed. Hence, the wood cells are not entangled at all or very little.

Mostafapour et al. (2013) described the technique to improve the mechanical properties of weld and it is the application of mechanical vibration to the molten pool. In this article, the effect of vibrating the part during welding on the mechanical properties of steel plates has been investigated in the tungsten inert gas (TIG) welding process. The plate is made of stainless steel 304 with $2 \mathrm{~mm}$ in thickness. A filler material has also been used for welding so that the effect of vibration can be observed on the weld pool region. The experimental tests have been performed under different welding conditions with respect to voltage, current, welding speed, vibrations amplitude, and frequency. Then, the resultant mechanical properties of the tested parts were measured. Kinugawa et al. (1992) proposed weld metal zone composed of two or more weld metals with different creep properties approach to produce welded joints with well balanced performance in terms of creep lifetime and ductility. Type 304 steel was welded by depositing a 308L and/or a 308 wire. The resulting weld metal zones are composed of a 'soft' weld metal with high ductility and 0 -to- 100 vol. \% of a 'hard' one with an extended creep lifetime but low ductility. The creep tests suggest that the creep behaviour of a welded joint may be controlled to obtain an optimum balance between its time-to-rupture and elongation.

Węglowska et al. (2012) studied to determine the influence of the welding conditions on the quality of vibration welded joints. The quality assessment was done on the base of tensile tests and microscopy examination, conducted on light microscopy and scanning electron microscopy (SEM). Results of the tensile test indicated that it is possible to achieve good quality of joints at the proper welding conditions. The light microscopy examination showed that the welding parameters influence the orientation of the glass fibres in the weld zone, on the continuity of the material in the weld and on the thickness of the weld. The results of the SEM indicated that the vibration welded joint is formed as a result of joining of the matrixes of two welded nylons. Jandali (2005) presented experimental results of vibration welding of a continuous fibre GMT composite of E-glass glass fibre reinforced polypropylene. Vibration welding parameters investigated were vibration time, clamping pressure and vibration amplitude. The effects of these parameters on penetration and lap shear strength of the composite were determined. It was shown that clamping pressure and vibration time should be properly selected to optimize the lap shear strength. Temperature measurements made during vibration welding showed the importance of these two parameters on the interface temperature required for proper vibration welding. Bates et al. (2004) studied the vibration welding of an industrial air intake manifold (AIM) made from nylon 66, nylon 6 and polypropylene all reinforced with $30 \%$ glass fibres. The meltdown-time profiles were measured and compared to those of simple lab-scale butt weld assemblies. The experimental results indicated that the meltdown rate of the manifold was controlled by the slower rate of transverse 
welding. The burst strengths of these aims at various welding conditions were also investigated. Results of finite element analysis indicated that the highest Von-mises stresses and the maximum normal principle stresses at the weld region of the AIM were comparable to the weld strength of corresponding lab-scale coupons, confirming that the initial failure occurred in the weld region.

$\mathrm{Xu}$ et al. (2007) studied on the effect of mechanical vibration on the toughness of the welded joint analysed from the point of view of fracture mechanics. The results indicate that the fracture toughness of the weld is obviously higher than that of HAZ (Heat-affected zone) and the CTOD (Crack tip opening displacement) value of the weld and HAZ under V-SAW condition is greater than that under N-SAW condition. And the difference in different regions of the welded joint is evidently reduced by applying $\mathrm{V}-\mathrm{SAW}$. Thereby, the fracture toughness is uniform. From fractography, it can be seen that the dimple density of the weld under V-SAW condition is greater than that under N-SAW condition. And HAZ is a weak region in welded joint.

Lu et al. (2006) investigated on the vibratory welding conditioning process in the electro-slag welding of blast furnace steel. The metallographs shows that a refined joint is produced. The residual stress, side bend property, tension and impact tests are carried out in different vibratory conditions $(0$ $\mathrm{g}, 0.3 \mathrm{~g}$ and $0.6 \mathrm{~g}$ ). The results of the test have fully proved that vibratory conditioning technology can effectively reduce residual stress and improve the comprehensive properties of weld joints. Rao et al. (2005) studied on the cyclic strain and stress of 304L stainless steel welded specimens on material testing system. To simulate the vibratory stress relief (VSR) processing, the tensile-compress cyclic loading was applied. The experimental results showed that the dynamic strain has feature of cyclic creep. Cyclic loading affected the creep and creep speed. The bigger the loading, the bigger the creep and the creep speed, and the longer time that the strain became stable. The residual stresses at weld toe were measured using X-ray diffraction method after different cyclic stress amplitude. According to the experimental results, the cyclic creep mechanism during VSR processing was presented.

Zhu et al. (2004) studied on vibratory conditioning technology (VCT) which was used in the routine electro-slag welding (ESW) for the first time. Three kinds of vibration accelerations: $0.3 \mathrm{~g}$ and $0.6 \mathrm{~g}$ were exerted on the weld position respectively. The test results show VCT can improve the side bend properties of weld joint of the steel used for blast furnace greatly. The qualification rate of $0.6 \mathrm{~g}$ reached $100 \%$. From metallograph, VCT can refine the grain effectively. The effect of grain refinement is more obvious as the acceleration of vibration is increasing. The grain refinement is one of the basic reasons for the improvement of bend property. Zhu et al. (2005) studied on vibratory conditioning technology that was used in the electro-slag welding of blast furnace steel and mechanical properties of welded joint were measured. The results have proved that vibratory conditioning technology can effectively improve the comprehensive properties of welded joints. Especially, at the $0.6 \mathrm{~g}$ (acceleration of gravity) vibratory state, the qualification rates of side bend performance are up to $100 \%$. Tucker et al. (2004) studied the impact of various modifications to the existing vibration welding technology which was examined, with the objective of increasing the current achievable weld strength of glass reinforced nylon. The introduction of a secondary vibratory motion perpendicular to the weld plane during welding resulted in strengths $20 \%$ higher than those of samples welded using the standard vibration welding process.

Rao et al. (2014) developed a new vibratory welding technique for inducing mechanical vibrations into the weld pool during welding process is proposed. The designed vibratory set-up produces the required vibrations at frequency with the amplitude and acceleration in terms of voltages. An increase in the flexural strength, impact strength, ultimate tensile strength, and hardness of the weld pieces at the HAZ is observed. The increase in mechanical proper-ties is because of the formation of refined microstructure during the weld pool solidification. This mechanism is responsible for the improvement in flexural strength, ultimate tensile strength, impact strength, and hardness of welded joints. From the experimental results, it is clear that the mechanical properties are improved consider-ably with the increase in the acceleration and amplitude of the specimens. Mechanical properties are improved with rise in the input voltage and vibration period. But these properties are not maintaining certain relation 
with the welding parameters. Rao et al. (2015) proved that the impact strength of the welded joints prepared under the influence of mechanical vibrations is found to be more compared to welded joints prepared without vibration. This is attributed to, as the weld pool solidifies, grains are not only limited in size but also dendrites are broken up before they grow large in size. The microstructure of the weld metal is observed to be improved. Therefore the Impact strength is improved in welded joints prepared under the influence of vibration compared to without vibration. Further, the Impact strength of welded joint has also been increased with respect to the increase in the voltage input to the vibromotor. There is also an improvement in the Impact strength with the increase in the acceleration and amplitude of the specimens.

Rao et al. (2015) described the major factors which influence the residual stresses due to welding with and without vibration. The residual stresses before and after welding has been affected, because of the geometry of the parts to be joined and restraint due to fixing welded parts in jigs and fixtures etc. Till computer-integrated manufacturing and operation becomes a reality, analysis of the whole history of the welded joints and its component materials, the determination of residual stresses in real welded structures will remain an inexact science. Post-weld vibratory treatment does not make any significant difference in the crystal structures as far as optical microscopy is concerned. Grain refinement occurs, hardness and tensile strength increases in the amplitude, acceleration, frequency of vibrated specimens. The increase of all these properties may be related to the orientation of the crystals. Rao et al. (2015) found that the flexural strength of the welded joints produced with mechanical vibrations is observed to be more compared to welded joints prepared without vibration. This is attributed to, as the weld pool solidifies, grains are not only limited in size but also dendrites are broken up before they grow large in size. The microstructure of the weld metal is observed to be improved. Therefore the Flexural strength is improved in welded joints prepared with vibration compared to without vibration. Further, the Flexural strength of welded joint has also been increased with respect to the increase in the voltage input to the vibromotor. There is also an improvement in the Flexural strength with the increase in the acceleration and amplitude of the specimens. Ramakrishna et al. (2012) found that the tensile strength of the welded joints prepared under the influence of mechanical vibrations is found to be more compared to welded joints prepared without vibration. This is attributed to, as the weld pool solidifies, grains are not only limited in size but also dendrites are broken up before they grow large in size. The microstructure of the weld metal is observed to be improved. Therefore the tensile strength and hardness are improved in welded joints prepared under the influence of vibration compared to without vibration. Further, the tensile strength of welded joint has also been increased with respect to the increase in the voltage input to the vibromotor. There is also an improvement in the tensile strength with the increase in the acceleration and amplitude of the specimens. Ramakrishna et al. (2013) proposed a new method for reduction of residual stresses vibrational load during welding is proposed. The proposed method is examined experimentally for some conditions. Two thin plates are supported on the supporting device and butt welded. By doing the experimentation the natural frequency was found by using at $70 \mathrm{~Hz}, 80 \mathrm{~Hz}$, and $84 \mathrm{~Hz}$. For these frequencies residual stresses greatly reduced at natural frequency of $84 \mathrm{~Hz}$. Second-side welding process were performed for which the residual stress slightly increased from $77 \mathrm{MPa}$ to $78 \mathrm{MPa}$. In this work welding of FEM was performed for mild steel IS2062 by using thermal and structural analysis to find out the residual stresses. The residual stresses were found by using Finite Element software for mild steel IS2062 is $118 \mathrm{MPa}$. Hence residual stresses can be greatly reduced by maintaining frequency of forced vibration nearer to the natural frequency of the specimen. Rao et al. (2012, 2013a,b, 2014a,b, 2015a,b,c, 2016 \& 2017a,b), Kalpana et al. (2013,2016,2017), Kalpana and Rao (2017). Suresh et al. (2017) proposed dynamic solidification technique during welding has been proposed to prompt the mechanical vibrations during welding of butt welded joints. It was presumed that butt welded joints arranged under vibratory conditions had high hardness with no loss of its ductility. Authors utilized the vibratory setup to affect the mechanical vibrations to the weld pool amid welding. Because of vibratory welding process, change of mechanical properties has been observed. It was inferred that the refined microstructure component was in charge of the change of impact strength, tensile strength, flexural strength and hardness of butt welded joints of mild steel plates. Authors observed that post weld vibratory treatment will not influence the crystal 
structure, the increase in all properties are related to the crystal structure only. Finally, General regression neural network technique (GRNN) based tool has been developed for estimating impact strength and hardness for given input parameters. GRNN is a proven prediction tool applied for various manufacturing applications including welding.

\section{Conclusions}

After careful review of past literature, vibratory assisted welding is best suited to overcome the drawbacks in PWHT, pulsed current welding and hybrid welding to improve the mechanical properties of weldments. Although PWHT, pulsed current welding and hybrid welding are used widely in practice, but they have certain drawbacks. For instance, Post Weld Heat treatment (PWHT) requires special tools and consumes more time, when compared with the remaining methods. High pulsed current reduce mechanical properties of welded joints compared to low pulsed current. If the thickness of sheets is increased, mechanical properties have been reduced in pulsed current welding. However, in hybrid welding, a large number of parameters should be carefully adjusted; otherwise this may lead to reduce the strength of the joint. To overcome the above drawbacks, a vibratory assisted welding widely used to improve the mechanical properties of welded joints. Finally, this paper concludes that the most of the researchers concentrated on the reduction of residual stresses and improvement in mechanical properties of welded joints using the vibratory system. Grain size and phase changes with respect to vibration parameters during welding in the presence of vibratory condition have not been studied as well. Dissimilar welding may also be attempted using vibratory assisted welding. The combined effect of welding parameters and vibratory parameters may also be studied.

\section{References}

Ahmad, R., \& Bakar, M. A. (2011). Effect of a post-weld heat treatment on the mechanical and microstructure properties of AA6061 joints welded by the gas metal arc welding cold metal transfer method. Materials \& Design, 32(10), 5120-5126.

Ahmed, S. R., Agarwal, L. A., \& Daniel, B. S. S. (2015). Effect of Different Post Weld Heat Treatments on the Mechanical properties of Cr-Mo Boiler Steel Welded with SMAW Process. Materials Today: Proceedings, 2(4-5), 1059-1066.

Aliha, M. R. M., \& Gharehbaghi, H. (2017). The effect of combined mechanical load/welding residual stress on mixed mode fracture parameters of a thin aluminum cracked cylinder. Engineering Fracture Mechanics. 213-228

An, J., Meng, F., Lv, X., Liu, H., Gao, X., Wang, Y., \& Lu, Y. (2012). Improvement of mechanical properties of stainless maraging steel laser weldments by post-weld ageing treatments. Materials \& Design, 40, 276-284.

Badji, R., Belkessa, B., Maza, H., Bouabdllah, M., Kahloun, C. (2004). Effect of post weld heat treatment on microstructure and mechanical properties of welded 2025 duplex stainless steel. Materials science forum, 467-470, pp. 217-222.

Balasubramanian, V., Ravisankar, V., \& Reddy, G. M. (2008). Effect of pulsed current welding on mechanical properties of high strength aluminum alloy. The International Journal of Advanced Manufacturing Technology, 36(3-4), 254-262.

Balasubramanian, K., Kesavan, D., \& Balusamy, V. (2011). Studies on the effect of vibration on hot cracking and grain size in AA 7075 aluminum alloy welding. International Journal of Engineering Science and Technology, 3(1).

Bates, P. J., Mah, J. C., Zou, X. P., Wang, C. Y., \& Baylis, B. (2004). Vibration welding air intake manifolds from reinforced nylon 66, nylon 6 and polypropylene. Composites part A: applied science and manufacturing, 35(9), 1107-1116.

Boonstra, M., Pizzi, A., Ganne-Chedeville, C., Properzi, M., Leban, J. M., \& Pichelin, F. (2006). Vibration welding of heat-treated wood. Journal of Adhesion Acience and Technology, 20(4), 359-369.

Dai, X., Zhang, H., Liu, J., \& Feng, J. (2015). Microstructure and properties of Mg/Al joint welded by gas tungsten arc welding-assisted hybrid ultrasonic seam welding. Materials \& Design, 77, 65-71.

Ding, J. K., Wang, D. P., Ying, W. A. N. G., \& Hui, D. U. (2014). Effect of post weld heat treatment on properties of variable polarity TIG welded AA2219 aluminium alloy joints. Transactions of Nonferrous Metals Society of China, 24(5), 1307-1316. 
Dryga, A. I. (2002). Influence of vibratory stabilizing treatment on decrease in residual stresses. Tyazheloe Mashinostroenie(Russia), 11,30-32.

Gomes, A. J. M., Jorge, J. C. F., de Souza, L. F. G., \& Bott, I. S. (2013). Influence of Chemical Composition and Post Welding Heat Treatment on the Microstructure and Mechanical Properties of High Strength Steel Weld Metals. In Materials Science Forum (Vol. 758, pp. 21-32). Trans Tech Publications.

Hsieh, C. C., Wang, P. S., Wang, J. S., \& Wu, W. (2014). Evolution of microstructure and residual stress under various vibration modes in 304 stainless steel welds. The Scientific World Journal, 2014.

Ibrahim, T., Yawas, D. S., \& Aku, S. Y. (2013). Effects of gas metal arc welding techniques on the mechanical properties of duplex stainless steel. Journal of minerals and materials Characterization and Engineering, 1(05), 222.

Jandali, G., \& Mallick, P. K. (2005). Vibration welding of a unidirectional continuous glass fiber reinforced polypropylene GMT. Composites Part A: Applied Science and Manufacturing, 36(12), 1687-1693.

Kalpana, J., \& Rao, P. (2017). Effect of vibratory welding process on hardness of dissimilar welded joints. Engineering Solid Mechanics, 5(2), 133-138.

Kalpana, J., Ramana, S. V., Rao, P. G., ChittiBabu, V., \& Santa Rao, K. (2013). Implementation of Generalized Regression Neural Network to Establish a Relation between Vibration Parameters and Time of Vibration for Welded Joints. IOSR Jouranl of Mechanical and Civil Engineering, 6(4), 36-42.

Kalpana, J., Rao, P. S., \& Rao, P. G. (2016). Effect of frequency on impact strength of dissimilar weldments produced with vibration. International Journal of Chemical Sciences, 14(3).

Kalpana, J., Rao, P. S., \& Rao, P. G. (2017). Investigation of Acceleration Effect on the Flexural Strength of Vibratory Dissimilar Welded Joints. Materials Focus, 6(2), 107-113.

Kinugawa, J., Monma, Y., Hongo, H., Yamazaki, M., \& Watanabe, T. (1992). Creep Behaviour of 304 Stainless Steel Welded Joints Composed of Two Different 308 Weld Metals. In Mechanical Effects of Welding (pp. 231-238). Springer, Berlin, Heidelberg.

Kuo, C. W., Lin, C. M., Lai, G. H., Chen, Y. C., Chang, Y. T., \& Wu, W. (2007). Characterization and mechanism of 304 stainless steel vibration welding. Materials transactions, 48(9), 2319-2323.

Leo, P., Renna, G., Casalino, G., \& Olabi, A. G. (2015). Effect of power distribution on the weld quality during hybrid laser welding of an Al-Mg alloy. Optics \& Laser Technology, 73, 118-126.

Li, C., \& Liu, L. (2013). Investigation on weldability of magnesium alloy thin sheet T-joints: arc welding, laser welding, and laser-arc hybrid welding. The International Journal of Advanced Manufacturing Technology, 65(1-4), 27-34.

Lu, Q., Chen, L., \& Ni, C. (2007a). Improving welded valve quality by vibratory weld conditioning. Materials Science and Engineering: A, 457(1), 246-253.

Lu, Q., Chen, L., and Ni, C. (2007b). Analysis of performance and microstructure of A105 steel welded joint under vibratory weld conditioning. ZhongguoJixieGongcheng/China Mechanical Engineering, 18(20), 2497-2501.

Lu, Q., Rao, D., Zhu, Z., and Chen, L. (2005). Influence of vibration on mechanical properties of electroslag weld joint. Preceedings of the International Conference on Mechanical Engineering and Mechanics, 2.

Lu, Q., Rao, D., Zhu, Z., Chen, L., \& Ni, C. (2006). Experimental study on mechanical properties of welded joint using vibratory conditioning technology. Jixie Gongcheng Xuebao(Chinese Journal of Mechanical Engineering), 42, 219-222.

Manikandan, M., Arivazhagan, N., Rao, M. N., \& Reddy, G. M. (2014). Microstructure and mechanical properties of alloy C-276 weldments fabricated by continuous and pulsed current gas tungsten arc welding techniques. Journal of Manufacturing processes, 16(4), 563-572.

Mao, J. W., LÜ, W. J., Wang, L. Q., Zhang, D., \& Qin, J. N. (2014). Microstructure and mechanical properties of GTA weldments of titanium matrix composites prepared with or without current pulsing. Transactions of Nonferrous Metals Society of China, 24(5), 1393-1399.

Mostafapour, A., \& Gholizadeh, V. (2014). Experimental investigation of the effect of vibration on mechanical properties of 304 stainless steel welded parts. The International Journal of Advanced Manufacturing Technology, 70(5-8), 1113-1124.

Munsi, A. S. M. Y., Waddell, A. J., \& Walker, C. A. (1999). Vibratory weld conditioning-the effect of rigid body motion vibration during welding. Strain, 35(4), 139-143.

Munsi, A. S. M. Y., Waddell, A. J., \& Walker, C. A. (2000). Vibratory weld conditioning: treatment of specimens during cooling. Proceedings of the Institution of Mechanical Engineers, Part L: Journal of Materials: Design and Applications, 214(3), 129-138. 
Munsi, A. S. M. Y., Waddell, A. J., \& Walker, C. A. (2001a). Modification of residual stress by post-weld vibration. Materials Science and technology, 17(5), 601-605.

Munsi, A. S. M. Y., Waddell, A. J., \& Walker, C. A. (2001b). The effect of vibratory stress on the welding microstructure and residual stress distribution. Proceedings of the Institution of Mechanical Engineers, Part L: Journal of Materials: Design and Applications, 215(2), 99-111.

Munsi, A. S. M. Y., Waddell, A. J., \& Walker, C. A. (2001c). Vibratory stress relief - an investigation of the torsional stress effect in welded shafts. The Journal of Strain Analysis for Engineering Design, 36(5), 453-464.

Prakash, J., Tewari, S. P., \& Srivastava, B. K. (2010). A review on solidification and change in mechanical properties under vibratory welding condition. International Journal of Engineering Science and Tehnology, 2(4).

Qinghua, L., Ligong, C., \& Chunzhen, N. (2008). Effect of vibratory weld conditioning on welded valve properties. Mechanics of Materials, 40(7), 565-574.

Ramakrishna, G., Kumar, C. A., Rao, P. G., \& Raman, D. S. (2012). A Finite Element Based Analysis of Residual Stresses of Welded Joint Through Mechanical Vibrations. In International conference on Advanced research in Mechanical engineering, 18th November.

Ramakrishna, G., Kumar, C. A., Rao, P. G., Chittibabu, V., \& Ramana, S. V. (2013). Finite Element Analysis Of Residual Stresses In Welded Joints Prepared Under The Influence Of Mechanical Vibrations. In International Conference on Latest Trends in engineering and Technology (ICLTET) during 27th April.

Ramakrishna, G., Rao, P. S., \& Rao, P. G. (2016). Methods To Improve Mechanical Properties of Welded Joints: View Point. International Journal of Mechanical Engineering and Technology, 7(6), 309-314.

Rao, D. L., CHEN, L. G., NI, C. Z., \& ZHU, Z. Q. (2005). The mechanism for vibratory stress relief of stainless steel. TRANSACTIONS-CHINA WELDING INSTITUTION, 26(9), 58.

Rao, D., Wang, D., Chen, L., \& Ni, C. (2007). The effectiveness evaluation of 314L stainless steel vibratory stress relief by dynamic stress. International Journal of Fatigue, 29(1), 192-196.

Rao, M. V., Rao, P. S., \& Babu, B. S. (2016). Investigate the Influence of Mechanical Vibrations on the Hardness of Al5052 Weldments. Indian Journal of Science and Technology, 9(39).

Rao, P. G., Prasad, C. L. V. R. S. V., Ramana, S. V., \& Sreeramulu, D. (2013a). Development of GRNN based tool for hardness measurement of homogeneous welded joint under vibratory weld condition. International Journal of Advanced Research in Engineering and Technology, 4(4), 50-9.

Rao, P. G., Rao, P. S., \& Deepak, B. B. V. L. (2017a). GRNN-Immune Based Strategy for Estimating and Optimizing the Vibratory Assisted Welding Parameters to Produce Quality Welded Joints. Engineering Journal, 21(3), 251-267.

Rao, P. G., Rao, P. S., \& Gopala Krishna, A. (2017b). A smart prediction tool for estimating the impact strength of welded joints prepared by vibratory welding process. Proceedings of the Institution of Mechanical Engineers, Part E: Journal of Process Mechanical Engineering, 231(2), 343-346.

Rao, P. G., Rao, P. S., \& Krishna, A. G. (2014a). Impact strength improvement of butt welded joints prepared by vibratory welding process. Journal of Manufacturing Technology Research, 6(3/4), 143.

Rao, P. G., Rao, P. S., \& Krishna, A. G. (2014b). Review on residual stresses in welded joints prepared under the influence of mechanical vibrations. Journal of Manufacturing Technology Research, 6(1/2), 33.

Rao, P. G., Rao, P. S., \& Krishna, A. G. (2015a). Evaluation of bending strength of the vibratory welded joint using regression technique. International Journal of Offshore and Polar Engineering, 25(03), $227-$ 230.

Rao, P. G., Rao, P. S., \& Krishna, A. G. (2015b). Flexural strength improvement of welded joints prepared by vibratory welding process. International Journal of Manufacturing, Materials, and Mechanical Engineering (IJMMME), 5(4), 1-16.

Rao, P. G., Rao, P. S., \& Krishna, A. G. (2015c). Mechanical properties improvement of weldments using vibratory welding system. Proceedings of the Institution of Mechanical Engineers, Part B: Journal of Engineering Manufacture, 229(5), 776-784.

Rao, P. G., Rao, P. S., Krishna, A. G., \& Sriram, C. V. (2013b). Improvement of tensile strength of a butt welded joints prepared by vibratory welding process. International Journal of Mechanical Engineering and Technology. 4(2), 53-61. 
Raveendra, A., \& Kumar, B. R. (2013). Experimental study on Pulsed and Non-Pulsed Current TIG Welding of Stainless Steel sheet (SS304). International Journal of Innovative Research in Science, Engineering and Technology, 2(6).

Ravikumar, B.V.R., Krishna Sai, B.L.N., and Rajashekhar, S. (2014).Evaluation of mechanical properties of AA6068-T6 Aluminium alloy using pulse \& non-pulse current GTAW process. International Journal of Innovative Research in Science Engineering and Technology, 3(12), 18136-18146.

Sawanishi, C., Ogura, T., Taniguchi, K., Ikeda, R., Oi, K., Yasuda, K., \& Hirose, A. (2014). Mechanical properties and microstructures of resistance spot welded DP980 steel joints using pulsed current pattern. Science and Technology of Welding and Joining, 19(1), 52-59.

Shibata, K., Sakamoto, H., \& Iwase, T. (2006). Laser-MIG hybrid welding of aluminium alloys. Welding in the World, 50(1-2), 28-34.

Smith, C., Pistorius, P. G. H., \& Wannenburg, J. (1997). The effect of a long post weld heat treatment on the integrity of a welded joint in a pressure vessel steel. International journal of pressure vessels and piping, 70(3), 183-195.

Sun, M. C., Sun, Y. H., \& Wang, R. K. (2004). The vibratory stress relief of a marine shafting of 35\# bar steel. Materials Letters, 58(3), 299-303.

Sun, M. C., Sun, Y. H., \& Wang, R. K. (2004). Vibratory stress relieving of welded sheet steels of low alloy high strength steel. Materials Letters, 58(7), 1396-1399.

Suresh, B. V., Rao, P. G., Musalaiah, G., \& Rao, P. S. (2017). Influence of Vibratory Weld Conditioning on Hardness of Lap Welded Joints. International Journal of Mechanical Engineering and Technology (IJMET), 8(1), 169-177.

Teng, F., Zhu, Z.-Q., Chen, G., and Ni, Z. (2006). Vibratory submerged arc welding technology. HanjieXuebao/Transactions of the China Welding Institution, 27(5), 109-112.

Tucker, B., Bates, P. J., Tucker, R., \& Sidiropolous, V. (2004). Improving vibration weld joint strength through process and equipment modifications. Science and technology of Welding and Joining, 9(5), 443-450.

Varga, J., Ehrenstein, G. W., \& Schlarb, A. K. (2008). Vibration welding of alpha and beta isotactic polypropylenes: mechanical properties and structure. Express Polymer Letters, 2(3), 148-156.

Węglowska, A., \& Pietras, A. (2012). Influence of the welding parameters on the structure and mechanical properties of vibration welded joints of dissimilar grades of nylons. Archives of Civil and Mechanical Engineering, 12(2), 198-204.

Xu, J. J., Chen, L. G., \& Ni, C. Z. (2006). Effects of vibratory weld conditioning on residual stresses and transverse contraction distortions in multipass welding. Science and Technology of Welding and Joining, 11(4), 374-378.

$\mathrm{Xu}$, J., Chen, L., \& Ni, C. (2007). Effect of vibratory weld conditioning on the residual stresses and distortion in multipass girth-butt welded pipes. International Journal of Pressure vessels and piping, 84(5), 298-303.

Yang, Y. P., Jung, G., \& Yancey, R. (2005, May). Finite element modeling of vibration stress relief after welding. In Proceedings of the 7th International Conference on Trends in Welding Research, Pine Mountain, Georgia.

Zhu, Z. Q., Chen, L. G., Rao, D. L., Ni, C. Z., Lu, L. X., \& Xu, L. X. (2005). Experimental study on electroslag weld of blast furnace steel using vibratory conditioning technology $[\mathrm{J}]$. Transactions of The China Welding Institution, 2, 017.

Zhu, Z. Y., Deng, C. Y., Wang, Y., Yang, Z. W., Ding, J. K., \& Wang, D. P. (2015). Effect of post weld heat treatment on the microstructure and corrosion behavior of AA2219 aluminum alloy joints welded by variable polarity tungsten inert gas welding. Materials \& Design (1980-2015), 65, 1075-1082.

Zhu, Z., Chen, L., Rao, D. \& Ni, C. (2004). Study on the improvement of electro-slag weld joint properties using vibratory conditioning technology. ZhongguoJixieGongcheng/China Mechanical Engineering, 15(22), 2051-2054.

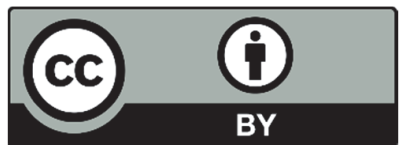

(C) 2017 by the authors; licensee Growing Science, Canada. This is an open access article distributed under the terms and conditions of the Creative Commons Attribution (CC-BY) license (http://creativecommons.org/licenses/by/4.0/). 